\title{
Relação da taxa de gestação com sêmen bovino congelado e testes de avaliação espermática in vitro
}

\author{
Jeanne Broch Siqueira ${ }^{1}$, José Domingos Guimarães², Eduardo Paulino da Costa ${ }^{2}$, Marc \\ Henry $^{3}$, Ciro Alexandre Alves Torres ${ }^{4}$, Marcos Vinícius Gualberto Barbosa da Silva ${ }^{5}$, \\ Thiago da Silva Silveira 6
}

\footnotetext{
1 Doutoranda FMVZ/UNESP, Botucatu.

${ }^{2}$ Laboratório de Reprodução Animal, UFV.

3 Departamento de Clínica e Cirurgia, Escola de Veterinária da UFMG.

4 Departamento de Zootecnia, UFV.

5 Embrapa Gado de Leite.

6 Médico Veterinário Autônomo Mestre em Reprodução Animal.
}

RESUMO - Avaliou-se a relação entre os testes complementares (teste hiposmótico, teste de termorresistência lento e teste de reação acrossômica) e os testes de avaliações convencionais (aspectos físicos e morfológicos) de sêmen bovino congelado/descongelado e os índices de prenhez. Os valores médios da motilidade espermática progressiva retilínea avaliados pelo teste de termorresistência foram de 53,48 (pós-descongelamento), 43,69 (60 minutos), 35,88 (120 minutos) e 33,04\% (180 minutos) e a porcentagem de células reativas ao teste hiposmótico foi de $37,89 \%$. Correlação positiva e de média intensidade foi encontrada para a motilidade espermática progressiva retilínea pós-descongelamento e o teste hiposmótico $(0,21)$. Entretanto, a correlação da motilidade aos 180 minutos com o teste hiposmótico foi alta $(0,64)$. A porcentagem de células que tiveram acrossoma reagido pós-descongelamento foi de $9,85 \%$, apresentando correlações negativas de média e alta intensidade (-0,25 e -0,46, respectivamente) com a motilidade espermática progressiva retilínea pós-descongelamento e após 3 horas de incubação. Não houve correlação dos testes complementares e da motilidade pós-descongelamento com a taxa de gestação. Nenhum parâmetro considerado isoladamente serviu para avaliar a capacidade fertilizante do sêmen congelado/ descongelado.

Palavras-chave: fertilidade, sêmen, testes complementares, touro

\section{Relationship between conception rates obtained by using bovine frozen semen and in vitro spermatic evaluation}

\begin{abstract}
The objective of this study was to evaluate the relationship between complementary (hiposmotic, thermoresistance and acrosome reaction tests) and conventional evaluations (physical and morphologic aspects) of bovine frozen/ thawed semen and conception rates. Average values for spermatic motility evaluated by thermo-resistance test were of $53.48 \%$ (post-thawed), 43.69\% (60 minutes), 35.88\% (120 minutes) and 33.04\% (180 minutes). The percentage of reactive cells observed for the hiposmotic test was $37.89 \%$. Average intensity was observed for post-thawing spermatic motility, positively correlated to hiposmotic test $(0.21)$. However, correlation between motility in the 180 minutes and hiposmotic test was high (0.64). The percentage of cells presenting post-thawing acrosome reaction was $9.85 \%$, which was negative correlated to postthawing $(-0.25)$ and after three hours of incubation (-0.46) spermatic motility. No correlation was observed for complementary tests and post-thawed motility and the conception rate. No one of the parameters evaluated in this study was individually able to indicate the fertilizing capacity of the frozen/thawed semen.
\end{abstract}

Key Words: complementary tests, semen, fertility, bull

\section{Introdução}

A criopreservação do sêmen bovino teve grandes avanços na década de 40, após a descoberta da função crioprotetora do glicerol (Polge, 1985). Entretanto, mesmo com as melhores técnicas atuais de preservação, obtém-se, em média, $50 \%$ de viabilidade da população espermática (Watson,
1995). Por ser uma célula complexa, o espermatozóide torna-se infértil quando um de seus fatores bioquímicos ou morfológicos é afetado. A avaliação de somente um desses aspectos não garante a condição de normalidade do outro, portanto, a combinação de vários fatores em uma análise multifatorial é mais apropriada para diagnóstico da funcionalidade e integridade do espermatozóide (Melo \& Henry, 1999). 
Parâmetros convencionais utilizados na avaliação espermática (número total de espermatozóides móveis, motilidade progressiva e morfologia) têm se mostrado limitados quanto à capacidade de predizer o potencial de fertilidade do sêmen. Um único teste é pouco eficaz pelo fato de que cada espermatozóide apresenta múltiplos compartimentos subcelulares com diferentes funções a serem avaliadas (Santos, 2003). Desse modo, alguns testes complementares foram desenvolvidos, como os testes de termorresistência (TTR), hiposmótico (teste HO) e de reação acrossômica.

O TTR foi proposto por Dimitropoulos (1967) para avaliação da fertilidade potencial de partidas de sêmen congelado de bovino, sendo, posteriormente, adaptado para as demais espécies. De acordo com Henry \& Neves (1998), o sêmen bovino é de boa qualidade quando, depois de submetido ao TTR, apresenta pelo menos $15 \%$ de motilidade espermática progressiva retilínea e escore 3 (escala de 1 a 5) de vigor espermático. No caso dos bovinos, a grande aceitação do TTR decorreu de sua relação positiva e alta com a fertilidade a campo, confirmada pela taxa de prenhez aos 60 e 90 dias, com relação de $0,78 \pm 0,04$ (Dimitroupolos, 1967).

Pelo teste HO, pode-se avaliar a atividade da membrana plasmática dos espermatozóides, característica importante para os diversos eventos fisiológicos que ocorrem durante a fertilização (capacitação, reação acrossômica e fusão dos espermatozóides com o ovócito). Segundo Jeyendran et al. (1984), espera-se que, quanto mais espermatozóides preservarem esta característica, melhor será a qualidade do sêmen (Nie \& Wenzel, 2001). Esta técnica caracteriza-se pelo transporte de fluidos através da membrana plasmática intacta dos espermatozóides sob condições hiposmóticas até o equilíbrio entre os compartimentos. Em solução hiposmótica, a célula espermática se expande com o influxo de fluidos, predominantemente na região das fibras da cauda. Com o inchaço das membranas, as fibras da cauda se dobram e enrolam - alterações facilmente observadas em microscópio de contraste de fase. Os espermatozóides "inchados" ou HO positivo (responsivo ao HO) são classificados como de membrana plasmática intacta (Drevius, 1972; Jeyendran et al., 1984; Inamassu et al., 1999).

A taxa de concepção depende, portanto, da probabilidade de os espermatozóides ejaculados passarem por completa modificação morfológica, bioquímica e biofísica, capacitando-se e permitindo a reação acrossômica quando em contato com a zona pelúcida do ovócito (Lenz et al., 1983; Yanagimachi, 1989). Por isso, avaliar a integridade do acrossoma é imprescindível para determinar a qualidade espermática, pois a reação acrossômica precisa ocorrer em sincronismo com o momento da fecundação.

A criopreservação eleva os níveis de cálcio intracelular, assim como a capacitação (Gillan et al., 1997; Watson, 2000). Conseqüentemente, a reação acrossomal em espermatozóides provenientes de sêmen congelado/ des congelado pode ser realizada em tempo menor que o necessário para sua induçãoin natura nos órgãos genitais da fêmea (O'Flaherty et al., 1999; Watson, 2000).

O objetivo neste estudo foi avaliar a relação entre os testes hiposmótico (avaliação da integridade funcional dos espermatozóides), de reação acrossômica e de termorresistência lento e os testes de avaliações convencionais (aspectos físicos e morfológicos) de sêmen bovino congelado/descongelado e os índices de prenhez.

\section{Material e Métodos}

Este estudo foi realizado no município de Magda - SP, localizado na região noroeste do estado de São Paulo. As partidas de sêmen foram escolhidas por sua maior utilização no programa de inseminação artificial de uma fazenda. Foram selecionadas 23 partidas de sêmen provenientes de 13 touros Nelore com idades variadas, utilizadas em um mínimo de 20 doses, de acordo com os registros dos dados referentes à estação de monta da fazenda (15/11/2002 a 15/01/2003).

As análises laboratoriais (avaliação física e morfológica do sêmen pós-descongelamento, teste de termorresistência, teste hiposmótico e teste de reação acrossômica) foram realizadas no laboratório de Reprodução Animal do Departamento de Medicina Veterinária da Universidade Federal de Viçosa (UFV).

Os ejaculados foram obtidos pelo método de eletroejaculação. Imediatamente após a coleta, o tubo coletor foi colocado em banho-maria a $37^{\circ} \mathrm{C}$, onde foi mantido durante todo o processo de avaliação do aspecto físico do sêmen. Após o cálculo da concentração espermática, foi adicionado diluente (tris-gema de ovo) para obtenção de uma proporção 1:1. O volume do diluidor acrescentado para completar a diluição final antes do resfriamento do sêmen foi calculado com base na concentração espermática do ejaculado, com a dose inseminante fixada em 25 milhões de espermatozóides/dose. Após a diluição total, o sêmen diluído foi conduzido à câmara fria a $4^{\circ} \mathrm{C}$ (resfriamento $\mathrm{e}$ equilíbrio do sêmen). Posteriormente, o sêmen foi envasado em palhetas de $0,25 \mathrm{~mL}$ e criopreservado até o momento de sua utilização. 
Para avaliação física do sêmen congelado/descongelado, foram considerados a motilidade espermática progressiva retilínea (expressa em porcentagem) e o vigor espermático (escala de 0 a 5 ). As partidas de sêmen foram descongeladas a $37^{\circ} \mathrm{C}$ por, no mínimo, 20 segundos e homogeneizadas em tubos eppendorf aquecidos a $37^{\circ} \mathrm{C}$, para posterior avaliação. Uma alíquota de sêmen foi acondicionada em tuboseppendorf contendo $1 \mathrm{~mL}$ de solução formol-salina tamponada (Hancoch, 1957) para posterior análise da morfologia espermática com utilização de microscopia de contraste de fase com aumento de 1250X sob objetiva de imersão (Olympus, modelo 41F). Foram avaliadas 400 células para determinação do percentual de espermatozóides normais e de anomalias de acrossoma, cabeça, peça intermediária e cauda. Posteriormente, os defeitos espermáticos foram classificados em defeitos espermáticos maiores, menores e totais, de acordo com Blom (1973).

Todas as características seminais dos animais incluídos neste experimento encontravam-se dentro dos padrões de normalidade para a espécie bovina preconizados pelo Ministério da Agricultura e pelo Colégio Brasileiro de Reprodução Animal (Henry \& Neves, 1998), com exceção das partidas 4 e 6 que apresentaram porcentagem de defeitos maiores e totais acima da recomendada para utilização em programas de inseminação artificial (29 e 35,5\% para a partida $4 ; 23,5$ e $27,5 \%$ para a partida 6 ). Contudo, estas partidas foram utilizadas em virtude da estratégia de cruzamento adotada na fazenda.

A longevidade dos espermatozóides de cada partida de sêmen foi avaliada pelo teste de termorresistência lento, de acordo com Vogler et al. (1991). O teste consistiu em recolocar uma amostra de sêmen de $0,25 \mathrm{~mL}$ (uma palheta) previamente descongelada a $37^{\circ} \mathrm{C}$ por, no mínimo, 20 segundos em um tubo eppendorf de $1,5 \mathrm{~mL}$ e submetê-la à incubação em banho-maria a $37^{\circ} \mathrm{C}$ por 3 horas. A amostra foi avaliada a cada 60 minutos (T0, T60, T120 e T180 minutos) quanto à motilidade espermática progressiva retilínea $(0$ a $100 \%)$ e ao vigor espermático ( 0 a 5 ) utilizando-se microscópio com aumento de 100 a 400X. Para classificação das características físicas do sêmen congelado/descongelado, empregou-se o padrão estabelecido por Henry \& Neves (1998).

Para o teste HO, acrescentou-se uma alíquota de $20 \mu \mathrm{L}$ de sêmen congelado/descongelado $\left(37^{\circ} \mathrm{C}\right.$ por, no mínimo, 20 segundos) a 1,0 mL de uma solução com frutose e citrato trisódico na concentração de $100 \mathrm{mOsm} / \mathrm{L}$, previamente aquecida a $37^{\circ} \mathrm{C}$ (Revell \& Mrode, 1994). Essa solução foi incubada por 60 minutos à mesma temperatura. Posteriormente, as amostras foram fixadas em $0,5 \mathrm{~mL}$ de solução de formol-salina tamponada. Posteriormente, uma amostra de $20 \mu \mathrm{L}$ da solução foi colocada entre lâmina e lamínula para contagem de 100 espermatozóides, em microscopia de contraste de fase com aumento de 1250x sob objetiva de imersão. As células foram classificadas quanto à presença ou não de cauda dobrada ou enrolada e o resultado foi determinado em porcentagem, efetuando-se o cálculo pela fórmula: $\mathrm{HO}$ $(\%)=(\%$ de alterações na região da cauda após teste $\mathrm{HO})$ - (\% de alterações na região da cauda dos espermatozóides antes do teste HO) (Melo \& Henry, 1999).

A reação acrossômica foi avaliada de acordo com o protocolo de coloração adotado por Bryan \& Akruk (1977). Espermatozóides com acrossoma normal apresentaram coloração vermelho-cereja a rosa na membrana acrossomal e região equatorial bem definida, enquanto aqueles com acrossoma reagido apresentaram a cabeça corada em rosa menos intenso e região equatorial da cabeça pouco definida. Foram contados 100 espermatozóides por partida de sêmen. A contagem foi realizada em microscopia comum com aumento de 1.250X, sendo avaliado o percentual de espermatozóides com acrossoma reagido.

As 23 partidas de sêmen congelado foram distribuídas entre os cinco retiros da Fazenda São Francisco, de acordo com os critérios de seleção da fazenda. As fêmeas foram submetidas ao máximo de quatro inseminações pelo método transcervical (deposição do sêmen no corpo do útero), não havendo posterior repasse com touro em monta natural. A rufiação com buçal marcador foi empregada no auxílio da identificação de estro. O momento ideal para inseminação foi determinado de acordo com o protocolo de inseminação de Trimberg \& Davis (1943), de modo que as fêmeas observadas em estro à tarde foram inseminadas na manhã do dia seguinte (7 às 8 h) e aquelas em estro pela manhã foram inseminadas no final da tarde do mesmo dia (18 às 19h). Quatorze diferentes inseminadores foram utilizados neste estudo.

Os critérios de inseminação das fêmeas respeitaram as orientações zootécnicas, conforme o programa de melhoramento genético adotado pela empresa. Assim, nem sempre a partida utilizada na primeira inseminação foi a mesma nas posteriores inseminações de determinada fêmea. Um total de 1.116 fêmeas - em todos osstatusreprodutivos: pluríparas (682 fêmeas, com bezerro ao pé), primíparas (105 fêmeas, com bezerro ao pé) e nulíparas (329 fêmeas) - foi distribuído aleatoriamente entre os cinco retiros da fazenda.

O diagnóstico de gestação foi realizado 30 dias após o término da estação de monta, por meio de avaliação ultrasonográfica (ultra-som Aloka, modelo SSD-500 acoplado a transdutor transretal linear de $5 \mathrm{MHz}$ ), considerando-se gestante quando visualizados a vesícula ou o embrião/feto 
no lume uterino. A taxa de gestação referente a cada partida foi calculada com base no número de fêmeas gestantes e no número de fêmeas inseminadas multiplicado por 100.

A análise estatística foi realizada utilizando-se o programa SAEG (UFV, 1998), de modo que, para todas as variáveis estudadas, foram efetuadas análises estatísticas descritivas (média, desvio-padrão, coeficiente de variação e frequiência cruzada). A correlação simples de Pearson foi utilizada para verificar relações entre as características estudadas. Análise de variância para modelos lineares e comparações entre médias pelo teste Tukey foram feitas com probabilidade de $5 \%$ de erro. Os dados qualitativos (taxa de gestação) foram agrupados em tabela de contingência e analisados pelo testes de qui-quadrado com probabilidade de $5 \%$ de erro.

\section{Resultados e Discussão}

A correlação entre a motilidade espermática progressiva retilínea pós-descongelamento e a taxa de fertilidade foi negativa e de média intensidade $(-0,22)$. Silva \& Vertstegen (1995) também observaram essa correlação no sêmen de cães e verificaram que as amostras de sêmen de motilidade mais alta após o descongelamento não foram as que proporcionaram taxas de prenhez mais elevadas. A motilidade espermática é fundamental para que os espermatozóides alcançem o ambiente uterino e o local de fertilização, sendo o critério mais usado na avaliação de sêmen antes e depois do processamento em laboratório. Entretanto, os resultados de avaliações microscópicas dependem de diversos fatores, como o meio utilizado para diluir o sêmen, as taxas de diluição, a temperatura e o tempo de realização durante a avaliação. Sabe-se que espermatozóides imóveis não são capazes de fertilizar, o que também não ocorre com todos os espermatozóides móveis, pois podem apresentar motilidade espermática alta após o descongelamento e não serem férteis em decorrência de danos em outras estruturas, como o acrossoma. Assim, são necessários outros testes para as análises do sêmen (Den Daas, 1997). Correa et al. (1997) não observaram diferença na motilidade espermática progressiva pós-descongelamento no sêmen de touros com baixa e alta fertilidade.

Alguns autores têm demonstrado os efeitos de defeitos espermáticos sobre a fertilidade a campo. Correa et al. (1997) avaliaram sêmen de bovino congelado/descongelado e verificaram relação de 0,59 entre fertilidade e morfologia espermática (porcentagem de espermatozóides normais), de modo que os menores valores estiveram associados à baixa fertilidade $(75,9 \%)$ e os maiores, ao alto nível de fertilidade $(82,2 \%)$. Casagrande et al. (1979) observaram correlação negativa entre a patologia total e os defeitos maiores com a fertilidade (-0,48 e $-0,51$ respectivamente) ao utilizarem sêmen congelado em rebanhos de diferentes regiões brasileiras.

Neste estudo, a relação entre defeitos morfológicos totais com a taxa de gestação foi baixa e negativa $(-0,11)$, resultado semelhante ao encontrado por Silva (2000) para monta natural e inseminação artificial e por Whitfield \& Parkinson (1992), que não observaram diferença entre touros quanto aos defeitos espermáticos maiores e totais e a fertilidade, medida pela taxa de prenhez após 90 dias da inseminação.

Nem sempre os testes de rotina utilizados são suficientes para determinar a taxa de fecundação, visto que as avaliações de sêmen são direcionadas para o enfoque populacional dos espermatozóides, o que pode conduzir a erros, pois nem todos os atributos dos espermatozóides (morfologia e habilidade de fecundação) podem ser compensados com o aumento do número de espermatozóides no órgão reprodutivo feminino) no momento da fecundação (Saacke et al., 1994). A importância dos fatores compensatórios na inseminação artificial reside no fato de limitarem o número mínimo de espermatozóides necessários por dose para se obter índice de fertilidade máximo (Schenk et al., 1987; Den Daas, 1997). Do mesmo modo, cada reprodutor apresenta um platô onde o aumento da concentração espermática não aumenta a fertilidade do macho (Vale Filho, 1989; Den Dass, 1997).

A concentração de espermatozóides por dose de sêmen congelado neste estudo $\left(25 \times 10^{6}\right)$ manteve-se nos limites preconizados por Vale Filho (1989), de 15 a $25 \times 10^{6}$, para obtenção de índices satisfatórios de fecundação, entretant o, a concentração de espermatozóides viáveis também deve ser considerada. Schenk et al. (1987) e Fonseca et al. (1995) revelaram, respectivamente, que concentrações abaixo de $10 \times 10^{6}$ e $6 \times 10^{6}$ espermatozóides viáveis por dose afetam as taxas de prenhez. Esses autores consideraram que, quando se deposita menor quantidade de sêmen, o sistema de transporte não permite que chegue à tuba uterina o percentual necessário para alta taxa de fertilização.

Considerando os resultados para motilidade espermática pós-descongelamento (Tabela 1), verifica-se que a menor porcentagem de células viáveis neste estudo foi de 10 milhões de espermatozóides por dose e, portanto, o número final de espermatozóides vivos/dose foi suficiente para resultados satisfatórios na taxa de gestação. Provavelmente isso explique a correlação negativa entre a motilidade espermática progressiva das partidas pós-descongelamento e as taxas de gestação obtidas. 
As médias de motilidade espermática progressiva retilínea para o sêmen congelado/descongelado avaliada durante o TTR foram de 53,48 $($ tempo $=0), 43,69($ tempo $=60$ minutos), 35,88 (tempo $=120$ minutos $)$ e $33,04 \%($ tempo $=180$ minutos). Considerando os resultados obtidos no tempo 180 do TTR, apenas uma partida foi descartada (partida 7 Tabela 1) por apresentar, segundo padrões citados por Henry \& Neves (1998), motilidade espermática progressiva e vigor espermático de $10 \%$ e 1 , respectivamente.

A correlação observada para o TTR (tempo $=180)$ e a taxa de gestação neste estudo foi positiva, mas de baixa intensidade $(0,13)$. Pesquisas sobre a correlação entre os resultados do TTR e a fertilidade em bovinos são escassas (Dimitropoulos, 1967; Arruda et al., 1992; Silva, 2000). No entanto, a grande aceitação do teste pode ser decorrente de sua correlação positiva e altamente significativa com a fertilidade a campo, avaliada por meio da taxa de prenhez aos 60 e 90 dias, com coeficiente de 0,78 (Dimitroupolos, 1967) e 0,84 entre fertilidade e longevidade do sêmen a $38^{\circ} \mathrm{C}$ (Ludwick et al., 1948, citados por Barnabe et al., 1981). Contudo, correlações de alta intensidade não foram obser- vadas em estudo posterior no qual os coeficientes de correlação significativos variaram de 0,35 a 0,40 da primeira à última avaliação do TTR e da taxa de gestação (Silva, 2000).

Observou-se grande variação na resposta dos espermatozóides ao teste $\mathrm{HO}$, fato relatado também por outros autores (Jeyendran et al., 1984; Neild et al., 1999; Bueno et al., 2001 a, b). Foram observados diferentes tipos de enrolamento de cauda, verificando-se desde pequena curvatura na ponta da cauda até cauda fortemente enrolada, com vários enrolamentos intermediários. Normalmente, nas células com alguma alteração de membrana, a resposta ao teste HO não é tão eficiente, ou seja, a membrana plasmática responde à solução hiposmótica de modo diferenciado (Melo \& Henry, 1999). Mesmo os espermatozóides aptos a responder ao teste $\mathrm{HO}$ após a criopreservação parecem apresentar algum comprometimento da membrana plasmática, o que seria a causa de resposta menos eficiente ao teste. Além disso, é provável que os filamentos do axonema da cauda sofram flexões de graus diferentes conforme a quantidade de água que entra na célula.

Tabela 1 - Parâmetros espermáticos de sêmen congelado/descongelado e respectivas taxas de gestação, de acordo com as partidas de sêmen

Table 1 - Spermatic parameters of frozen/thawed semen and respective pregnancy rates obtained by each frozen semen sample

\begin{tabular}{|c|c|c|c|c|c|c|c|}
\hline $\begin{array}{l}\text { Partida } \\
\text { Sample }\end{array}$ & $\operatorname{MOT}(\%)$ & MOTT180 (\%) & teste $\mathrm{HO}(\%)$ & RA $(\%)$ & IA $(n)$ & $\operatorname{GEST}(\mathrm{n})$ & $\mathrm{TxG}(\%)$ \\
\hline 1 & 70 & 30 & 32,5 & 8,5 & 27 & 13 & 48,15 \\
\hline 2 & 45 & 20 & 41,5 & 10 & 38 & 32 & 84,21 \\
\hline 3 & 50 & 45 & 42,5 & 8,5 & 35 & 27 & 77,14 \\
\hline 4 & 45 & 30 & 42,5 & 13 & 34 & 22 & 64,71 \\
\hline 5 & 45 & 30 & 35,5 & 8,5 & 33 & 24 & 72,73 \\
\hline 6 & 45 & 20 & 35,5 & 8,5 & 129 & 70 & 54,26 \\
\hline 7 & 50 & 10 & 28,5 & 21 & 42 & 23 & 54,76 \\
\hline 8 & 40 & 30 & 37 & 11 & 38 & 27 & 71,05 \\
\hline 9 & 60 & 50 & 44,5 & 10 & 35 & 21 & 60,00 \\
\hline 10 & 60 & 30 & 45 & 8,5 & 33 & 21 & 63,64 \\
\hline 11 & 40 & 30 & 47 & 9 & 48 & 30 & 62,50 \\
\hline 12 & 40 & 35 & 38,5 & 15 & 59 & 34 & 57,63 \\
\hline 13 & 60 & 40 & 43 & 9,5 & 36 & 27 & 75,00 \\
\hline 14 & 65 & 30 & 31 & 8,5 & 57 & 20 & 64,91 \\
\hline 15 & 60 & 60 & 59 & 7 & 74 & 57 & 77,03 \\
\hline 16 & 40 & 20 & 27,5 & 11 & 57 & 47 & 82,46 \\
\hline 17 & 40 & 30 & 22 & 7 & 39 & 27 & 69,23 \\
\hline 18 & 75 & 40 & 45 & 7,5 & 85 & 55 & 64,70 \\
\hline 19 & 70 & 40 & 35 & 11,5 & 58 & 42 & 72,41 \\
\hline 20 & 75 & 40 & 38,5 & 7,5 & 68 & 28 & 41,18 \\
\hline 21 & 60 & 30 & 31 & 9,5 & 29 & 15 & 51,72 \\
\hline 22 & 45 & 30 & 32,5 & 7 & 38 & 11 & 28,95 \\
\hline 23 & 50 & 40 & 36,5 & 9,5 & 24 & 17 & 70,83 \\
\hline Média & 53,48 & 33,04 & 37,89 & 9,86 & 48,52 & 30,00 & 63,87 \\
\hline \multicolumn{8}{|l|}{ Mean } \\
\hline Desvio & 11,91 & 10,74 & 7,91 & 3,11 & 23,65 & 14,93 & 13,27 \\
\hline Deviation & & & & & & & \\
\hline
\end{tabular}

MOT (\%): motilidade espermática progressiva retilínea, em porcentagem; MOT/T180 (\%): motilidade espermática progressiva retilínea no tempo 180 do TTR, em porcentagem; RA (\%): espermatozóides reagidos pelo teste de reação acrossômica, em porcentagem; teste HO (\%): espermatozóides que reagiram ao teste hiposmótico, em porcentagem; IA (n): número de fêmeas inseminadas; GEST (n): número de fêmeas gestantes; TxG: taxa de gestação, em porcentagem. MOT (\%): spermatic motility, in percentage; $M O T / 180$ (\%): spermatic motility in time 180 TTR, in percentage; RA (\%): acrossomic reaction, in percentage; HO test (\%): amount of spermatic reaction to the hiposmotic test, in percentage; IA (n): number of inseminated females; GEST (n): number of pregnant females; TxG: pregnancy rate, in percentage. 
A porcentagem média de espermatozóides reativos ao teste $\mathrm{HO}$ encontrada neste estudo foi de 37,89\% (Tabela 1) e apresentou (com exceção da partida 11) valores inferiores ao de motilidade espermática progressiva, indicando a presença de células móveis, porém sem a membrana plasmática íntegra.

A baixa resposta ao teste $\mathrm{HO}$ após a criopreservação provavelmente foi ocasionada por danos na cauda dos espermatozóides durante o processo de congelamento/ descongelamento, o que diminuiu a capacidade desses espermatozóides de reagirem ao aumento de volume celular, em resposta à baixa osmolaridade (Hossain et al. 1998), ou em decorrência das condições de estoque e manuseio do sêmen (Correa \& Zavos, 1994). Além disso, o próprio meio de congelamento (hiperosmótico) pode acarretar ruptura de membrana, pois o estresse osmótico pode induzir, além de alterações nas estruturas das membranas, mudanças nas estruturas microtubulares da cauda (Correa \& Zavos, 1994).

Células funcionalmente íntegras e imóveis também foram observadas na partida 11 . Watson (1995) relatou que, embora o declínio da motilidade espermática possa ser explicado pelas mudanças no transporte ativo e na permeabilidade da membrana plasmática da região da cauda dos espermatozóides, é possível também que alterações na energia disponível ou danos aos elementos do axonema contribuam para esse declínio, resultando, portanto, em baixa motilidade, sem alto índice de lesão da membrana plasmática.

A correlação entre o número de espermatozóides reativos ao teste $\mathrm{HO}$ e a motilidade progressiva retilínea pós-descongelamento foi positiva e de média intensidade $(0,21)$, o que corrobora os resultados obtidos por Borges (2003) com partidas de sêmen bovino congelado/descongelado. Entretanto, correlações positivas e de alta intensidade foram encontradas por Correa \& Zavos (1994), em sêmen bovino criopreservado, e por Bueno et al. (2001 a, b), em sêmen de cão, enquanto correlações positivas e de baixa intensidade foram encontradas por Neild et al. (1999) e Snoeck et al. (2007), em sêmen criopreservado de eqüino, e Inamassu et al. (1999), em sêmen fresco de cão.

Observou-se correlação alta e positiva entre o teste HO e o TTR no tempo $180(0,64)$. Resultados similares foram encontrados por Bueno et al. (2001 a, b) para teste HO x TTR no tempo 120 em sêmen criopreservado de cão. Considerando estes resultados, presume-se que espermatozóides com funcionalidade da membrana plasmática após a criopreservação permaneceram viáveis por mais tempo.

Neste estudo, foi encontrada correlação positiva e de média intensidade $(0,23)$ para espermatozóides reativos ao teste $\mathrm{HO}$ e a taxa de gestação, embora altas correlações para estas características de sêmen bovino congelado/ descongelado tenham sido encontradas em programas de inseminação artificial (Revell \& Mrode, 1994; Correa et al., 1997). Entretanto, em testes realizados in vitro (FIV), observaram-se correlações baixas e negativas entre teste HO de sêmen congelado e fertilidade (Rota et al., 2000) e entre o teste $\mathrm{HO}$ e o sêmen fresco de eqüino (Neild et al., 2000).

Segundo Den Dass (1992), a relação entre algumas características seminais (avaliadas em laboratório) e a fertilidade tem sido inconsistente, em decorrência do número definido de espermatozóides por inseminação, às vezes tão elevado que reduz as chances de a população espermática com a alteração detectada influenciar os resultados de fertilidade. Isso pode explicar as baixas correlações encontradas neste estudo, visto que o número de espermatozóides utilizados por dose $\left(25 \times 10^{6}\right)$ foi superior à dose mínima recomendada para partidas de sêmen congelado/descongelado de bovinos. Mesmo considerando apenas o número de espermatozóides com membrana plasmática intacta, avaliada pelo teste $\mathrm{HO}$, obteve-se o mínimo de cinco milhões e meio de espermatozóides viáveis para a partida 17 , que apresentou apenas $22 \%$ de células íntegras pelo teste HO.

Neste estudo, observou-se média de $9,85 \%$ de células com acrosoma reagido para as 23 partidas (Tabela 1). Correa et al. (1997) obtiveram valores semelhantes ao avaliarem a integridade acrossomal de sêmen congelado bovino pelo método Naftol Amarelo/Eritrosina B. Esses autores observaram valores médios de 78,2 e 83,7\% de acrossomas não reagidos para touros de baixa e alta fertilidade, respectivamente. Observaram ainda correlação negativa e de média intensidade $(-0,25)$ para o teste de reação acrossômica e a motilidade progressiva espermática pós-descongelamento. De certo modo, os espermatozóides podem apresentar motilidade alta, mas não serem férteis por problemas relacionados a alterações acrossomais. No entanto, a correlação entre o teste de reação acrossômica e a motilidade espermática no tempo 180 do TTR foi negativa e de alta intensidade $(-0,46)$.

Correlação negativa e de média intensidade $(-0,22)$ entre o teste $\mathrm{HO}$ e o de reação acrossômica foi observada, indicando que maiores valores para número de células positivas ao teste $\mathrm{HO}$ correlacionaram-se a menores porcentagens de células com acrossomas reagidos, indicando integridade da membrana plasmática acrossomal.

Não houve correlação entre o teste de reação acrossômica e a taxa de gestação das partidas analisadas 
(P>0,05). A técnica de coloração Naftol Amarelo foi usada por alguns autores (Parrish et al., 1988; Steinholt et al., 1991) para avaliação do acrossoma. Contudo, seu uso isoladamente pode induzir a erros de estimativa, visto que as células mortas que sofrem lise acrossomal coram-se como as células vivas que sofreram RA verdadeira. Esta técnica não permite distinguir os espermatozóides vivos dos mortos. Desta forma, os espermatozóides reagidos e que conseqüentemente não estavam aptos a fecundar o ovócito poderiam pertencer à população de espermatozóides mortos e não poderiam ser considerados para correlação com a fertilidade. Por isso, torna-se essencial a determinação da viabilidade celular por meio de outra técnica de coloração ou com o uso de uma coloração que possa avaliar tanto a viabilidade quanto a integridade do acrossoma.

Observou-se diferença na taxa de gestação entre as partidas estudadas quando analisadas pelo teste qui-

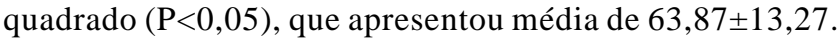
A baixa taxa de gestação encontrada pode ter sido ocasionada pelas condições inerentes de cada serviço, como qualidade do pessoal, ou outras características do sêmen, qualidade da tecnologia de congelamento empregada e qualidade do rebanho.

A taxa de gestação foi afetada pela eficiência dos inseminadores $(\mathrm{P}<0,05)$. Entretanto, os resultados foram pouco influenciados (Tabela 2). Observa-se que 61,75; 67,18 e $72,92 \%$ das fêmeas ficaram gestantes nos 10 , 2 으 3 o serviços, respectivamente. Além disso, os índices de serviço encontrados foram de $1.62,1.49$ e 1.37 , considerados bons em relação ao que se considera ideal para sêmen nacional (Porto et al., 1993). Não foi observada diferença quanto ao número de serviços em relação à taxa de gestação $(\mathrm{P}>0,05)$. O quarto serviço não foi considerado nesta análise, visto que apenas seis fêmeas foram inseminadas nestas condições.

Quanto aos cinco retiros da fazenda, foram encontradas diferenças entre os retiros 1,3 e $4(\mathrm{P}<0,05)$, com valores de 79,17; 48,60 e 43,14 respectivamente. Apesar dos resultados satisfatórios para as taxas de gestação, acredita-se que alguns fatores relacionados ao retiro (exemplo: estresse dos animais no momento da inseminação) podem ter influenciado na diferença encontrada.

Neste estudo, não houve diferença quanto ao status reprodutivo das fêmeas em relação à taxa de gestação ( $\mathrm{P}>0,05$ ), sendo obtidos valores de 61,44; 68,57 e 65,55\% para pluríparas, primíparas e nulíparas, respectivamente. Resultados semelhantes foram descritos por Fonseca et al. (1995), segundo os quais a categoria das fêmeas também não influenciou no resultado final de fertilidade. Em princípio,
Tabela 2 - Taxa de gestação em rebanho de fêmeas Nelore submetidas a inseminação artificial

Table 2 - Pregnancy rate of Al Nelore females according to the number of inseminations

\begin{tabular}{lrrrrr}
\hline $\begin{array}{l}\text { Numero de serviços } \\
\text { Number of inseminations }\end{array}$ & IA (n) & GEST (n) & TxG (\%) & \multicolumn{2}{c}{$\mathrm{X}^{2}$} \\
\hline 1 & 800 & 494 & 61,75 & $\mathrm{a}$ & \\
2 & 262 & 176 & 67,18 & $\mathrm{a}$ & $\mathrm{a}$ \\
3 & 48 & 35 & 72,92 & $\mathrm{a}$ & $\mathrm{a}$ \\
4 & 6 & 2 & 33,33 & - & - \\
Total & 1.116 & 707 & $63,35 \%$ & &
\end{tabular}

IA (n): número de fêmeas inseminadas; GEST (n): número de fêmeas gestantes; TXG (\%): taxa de gestação em porcentagem.

${ }^{2}=(P=0,05) ; \mathrm{GL}_{1}=3,84$, com exceção do 4 을 serviço, que foi excluído da análise.

$a=$ Valores seguidos de letras minúsculas iguais na mesma coluna não diferem entre si.

IA (n): number of inseminated females; GEST (n): number of pregnant females; TXG (\%): pregnancy rate in percentage.

$\chi^{2}=(P=0.05) ; G L_{1}=3.84$, except for four services, which were excluded from the analysis. $a=$ Values followed by the same letter in the same column are not statistically different.

a categoria "primípara" deveria apresentar resultadoinferior, em virtude dos efeitos negativos da cria ao pé sobre a eficiência reprodutiva, todavia, as condiçõesadequadas de manejo a que o rebanho foi submetido durante o ano provavelmente nivelaram todas as categorias no mesmo patamar de fertilidade.

\section{Conclusões}

Não se observou correlação entre os testes complementares e a motilidade pós-descongelamento com a taxa de gestação. Os parâmetros espermáticos de morfologia e motilidade espermática progressiva, bem como os testes complementares (teste HO, TTR e RA), são insuficientes para predizer o potencial fecundante de partidas de sêmen congelado/descongelado de bovinos.

\section{Agradecimento}

Ao Professor José Domingos Guimarães, pela orientação neste estudo; ao Departamento de Medicina Veterinária da Universidade Federal de Viçosa; e à Agropecuária CFM Ltda-Fazenda São Francisco, representada pelo Sr. Rodney Hobbs, pela colaboração e pela doação das amostras de sêmen e pela disponibilização dos resultados de campo.

\section{Literatura Citada}

ARRUDA, R.P.; BARNABE, V.H.; ALENCAR, M.M. et al. Avaliação de sêmen congelado de bovinos. Provas lenta e rápida de termoresistência: efeitos sobre a fertilidade. Brazilian Journal of Veterinary Research and Animal Science, v.29, n.1, p.131 $137,1992$. 
BARNABÉ, V.H.; BARNABÉ, R.C.; VISINTIN, J.S. et al. Estudo comparativo entre as provas rápida e lenta de termo resistência para avaliação de sêmen congelado. Revista Brasileira de Reprodução Animal, v.4, n.3-4, p.7-12, 1981.

BLOM, E. The ultra structure of some characteristic sperm defects and a proposal for a new classification of the bull spermiogram. Nordisk Veterinarer Medicin, v.53, p83-391, 1973.

BRYAN J.H.D.; AKRUK, S.R. A naphthol yellow S and erithrosin B staining procedure for use in studies of the acrosome reaction of rabbit spermatozoa. Stain Technology, v.52, p.47-51, 1977.

BORGES, J.C. Utilização de antioxidantes associados ou não a emulsificante na criopreservação do sêmen bovino. Viçosa, MG: Universidade Federal de Viçosa, 2003. 57p. Dissertação (Mestrado em Medicina Veterinária) - Universidade Federal de Viçosa, 2003.

BUENO, R.; COSTA, E.P.; GUIMARÃES, J.D. et al. Qualidade espermática do sêmen criopreservado de cães: I - efeito do meio diluidor. Arquivo Brasileiro de Medicina Veterinária e Zootecnia, v.53, n.3, 2001a. Disponível em: <http:// www.scielo.br/scielo.php?script $=$ sci_arttext $\&$ pid $=S 0102-$ 09352001000300016\&lng=pt\&nrm=iso>. Acesso em: 31/10/2006.

BUENO, R.; COSTA, E.P.; GUIMARÃES, J.D. et al. Qualidade espermática do sêmen criopreservado de cães: II - Efeito do protocolo de resfriamento. Arquivo Brasileiro de Medicina Veterinária e Zootecnia, v.53, n.3, 2001b. Disponível em: $<$ http://www.scielo.br/scielo.php?script=sci_arttext\&pid= $\mathrm{S} 0102-9352001000300017 \& \operatorname{lng}=\mathrm{pt} \& \mathrm{nrm}=\mathrm{iso}>$. Acesso em: $01 / 11 / 2006$

CASAGRANDE, J.F.; PINHEIRO, L.E.L.; ALMEIDA, C.A. et al. Patologia espermática agrupada segundo BLOM (1972) na avaliação de sêmen para conelação. Revista Brasileira de Reprodução Animal, v.3, n.2, p.19-23, 1979.

CORREA, J.R.; ZAVOS, P.M. The hypoosmotic swelling test: its employment as assay to frozen-thawed bovine sperm membrane. Theriogenology, v.42, p.351-360, 1994.

CORREA, J.R.; PACE, M.M.; ZAVOS, P.M. Relationships among frozen-thawed sperm characteristics assessed via the routine semen analysis, sperm functional tests and fertility of bulls in an artificial insemination program. Theriogenology, v.48, p.721-731, 1997

DIMITROPOULOS, R. La signification du test de la thermorésistance dans láppreciation de la valeur fécondant du sperma congele. Animal Medicin Veterinary, v.4, p.215224, 1967

DEN DAAS, N.J.H.G. Prediction of bovine male fertility . Lelystad: Institute for Animal Science and Health, 1997. 168p. Thesis (Doctor in Reproduction Science) - Institute for Animal Science and Health, 1997.

DEN DAAS, N.J.H.G. Laboratory assessment of semen characteristics. Animal Reproduction Science, v.28, p.8794, 1992.

DREVIUS, L.O. The permeability of bull spermatozoa to water, polyhydric alcohols and univalent anions and the effects of the anions upon the kinetic activity of spermatozoa and sperm models. Journal of Reproduction and Fertility, v.28, p.4154, 1972.

FONSECA, V.O.; VALE FILHO, V.R.; CHOW, L.A. Efeito da concentração espermática sobre a taxa de gestação de vacas zebus (Bos taurus indicus). Arquivo Brasileiro de Medicina Veterinária e Zootecnia, v.47, n.5, p.687-697, 1995.

GILLAN, L.; EVANS, G.; MAXWELL, W.M.C. Capacitating status and fertility of fresh and frozen-thawed ram spermatozoa. Reproduction Fertility and Development, v.9, p.481-487, 1997.

HANCOCH, J.L. The morphology of boar spermatozoa. Journal Reproduction Microscopy Science, v.76, p.84-97, 1957.

HENRY, M.; NEVES, J.P. Manual para exame andrológico e avaliação de sêmen animal. 2.ed. Belo Horizonte: Colégio Brasileiro de Reprodução Animal, 1998. 49p.
HOSSAIN, A.M.; RIZK, B.; BARIK, S. et al. Time course of hypoosmotic swellings of human spermatozoa: evidence or ordered transition between swelling subtypes. Human Reproduction, v.13, p.1578-1583, 1998.

INAMASSU, A.; VECHI, E.; LOPES, M.D. Viabilização do teste hipo-osmótico em cães e sua relação com outras variáveis espermáticas. Revista Brasileira de Reprodução Animal, v.23, n.3, p.302-304, 1999.

JEYENDRAN, R.S.; van der VER, H.H.; PEREZ-PELAEZ. M. et al. Developement of an assay the functional integrity of the human sperm membrane and its relationship to other semen characteristics. Journal of Reproduction and Fertility, v.70, p.219-228, 1984.

LENZ, R.W.; BALL, G.D.; LOHSE, J.K. et al. Chondroitin sulfate facilitates an acrosome reaction in bovine spermatozoa as evidence by light microscopy, electron microscopy and in vitro fertilization. Biology of Reproduction, v.28, p.683-690, 1983.

MELO, M.I.V.; HENRY, M. Teste hiposmótico na avaliação de sêmen eqüino. Arquivo Brasileiro de Veterinária e Zootecnia, v.51, n.1, p.71-78, 1999.

NEILD D.; CHAVES G.; FLORES M. et al. Hypoosmotic test in equine spermatozoa. Theriogenology, v.51, p.721-727, 1999.

NEILD, D.M.; CHAVES, M.G.; FLORES, M. et al. The HOS test and its relationship to fertility in the stallion. Andrology v.32, p.351-355, 2000.

NIE, G.J.; WENZEL, J.G.W. Adaptation of the hypoosmotic test to assess functional integrity of stallion spermatozoal plasma membranes. Theriogenology, v.55, p.1005-1018, 2001.

O'FLAHERTY, C.M.; BEORLEGUI, N.B.; BECONI, M.T. Reactive oxygen species requirements for bovine sperm capacitation and acrosome reaction. Theriogenology, v.52, p.289-301, 1999.

PARRISH, J.J.; SUSKO-PARRISH, J.L.; WINER, M.A. et al. Capacitation of bovine sperm by heparin. Biology of Reproduction, v.38, p.1171-1180, 1988.

POLGE, C. Sperm freezing: Past, present and future. In: JOHNSON, L.A.; LARSSON, K. (Eds.) Deeping freezing of boar semen. Beltsville: USDA, 1985. p.167-173.

PORTO, P.F.A.; PINHEIRO, L.E.L.; KUABARA, M.Y. et al. Comparações de índices de gestação obtidos com o uso a campo de sêmen nacional e importado. Revista Brasileira de Reprodução Animal, p.105-107, 1993 (suppl. 4).

REVELL, S.G.; MRODE, R.A. An osmotic resistance test for bovine semen. Animal Reproduction Science, v.36, p.77-86, 1994.

ROTA, A.; PENZO, N.; VICENTI, L. et al. Hipoosmotic swelling (HOS) as a screening assay for testing in vitro fertility of bovine spermatozoa. Theriogenology, v.53, p.1415-1420, 2000.

SAACKE, R.G.; NADIR, S.; DALTON, J. et al. Accessory sperm evolution and bull fertility and update. Technical Conference on Artificial Insemination and Reproduction, v.15, p.5767, 1994.

UNIVERSIDADE FEDERAL DE VIÇOSA - UFV. Sistemas de Análises Estatísticas e Genéticas - SAEG. (Versão 7.0). Viçosa, MG: 1998. (CD-ROM).

SANTOS, G.C.J. Viabilidade de sêmen eqüino congelado em meios diluidores de diferentes composições. Belo Horizonte: Universidade Federal de Minas Gerais, 2003. 58p. Dissertação (Mestrado Medicina Veterinária) - Universidade Federal de Minas Gerais, 2003.

SCHENK, R.P.; AMANN, R.P.; ALLEN, C.H. Effects of extender and insemination dose on post-thaw quality and fertility of bovine sperm. Journal of Dairy Science, v.70, p.1458-1464, 1987.

SILVA, M.R. Taxa de gestação e avaliação de sêmen congelado/ descongelado de touros da raça Nelore utilizando testes convencionais e de adesão in vitro de espermatozóides à zona pelúcida de ovócitos bovinos imaturos. Viçosa, MG: Universidade Federal de Viçosa, 2000. 75p. Dissertação (Mestado em Medicina Veterinária) - Universidade Federal de Viçosa, 2000. 
SILVA, L.D.M.; VERTSTEGEN, J.P. Comparisons between three different extenders for canine intrauterine insemination with frozen-thawed spermatozoa. Theriogenology, v.44, p.571579, 1995

SNOECK, P.P.N.; HENRY, M.; MELO, M.I.V. Efeito de diferentes diluidores sobre a viabilidade espermática pós-descongelação em eqüinos. Arquivo Brasileiro de Medicina Veterinária e Zootecnia, 2007 (no prelo).

STEINHOLT, H.C.; CHANDLER, J.E.; TIRADO, V. Evaluating acrosome reaction steps with brightfield and defferential interference contrast microscopy techniques. Journal of Dairy Science, v.74, p.3822-3826, 1991.

TRIMBERG, W.; DAVIS, H.P. Conception rate in dairy cattle by artificial insemination at various stages of estrus. Nebraska: Research Bull University of Nebraska, 1943. 14p.

VALE FILHO, V.R. Padrões de sêmen bovino para o Brasil. Análise e sugestões. In: CONGRESSO BRASILEIRO DE REPRODUÇÃO, 8., 1989, Belo Horizonte. Palestras... Belo Horizonte: Colégio Brasileiro de Reprodução Animal, 1989. p.94-118.

VOGLER, C.J.; SAACKE, R.G.; BAME, J.H. et al. Effect of scrotal insulation on viability of cryopreserved bovine semen. Journal of Dairy Science, v.74, p.3827-3835, 1991.
YANAGIMACHI, R. Sperm capacitation and gamete interaction. Journal Reproduction and Fertility, v.38, p.27-33, 1989 (suppl.).

WATSON, P.F. Recent developments and concepts in the cryopreservation of spermatozoa and the assessment of their postthawing function. Reproduction Fertility and Development, v.7, p871-891, 1995.

WATSON, P.F. The causes of reduced fertility with cryopreserved semen. Animal Reproduction Science, v.60, p.481-492, 2000.

WHITFIELD, C.H.; PARKINSON, T.J. Relationship between fertility of bovine semen and in vitro induction of acrossome reactions by heparin. Theriogenology, v.38, p.11-20, 1992. 